\title{
BMJ Open Quality See You in 7: improving acute myocardial infarction follow-up care
}

\author{
Alex Batten, ${ }^{1}$ Cassie Jaeger, ${ }^{1}$ David Griffen, ${ }^{2}$ Paula Harwood, ${ }^{1}$ Karen Baur ${ }^{1}$
}

To cite: Batten A, Jaeger C, Griffen D, et al. See You in 7 : improving acute myocardial infarction followup care.BMJ Open Quality 2018;7:e000296. doi:10.1136/ bmjoq-2017-000296

- Additional material is published online only. To view please visit the journal online (http://dx.doi.org/10.1136/ bmjoq-2017-000296).

Received 18 December 2017 Revised 26 April 2018 Accepted 2 June 2018
Check for updates

${ }^{1}$ Department of Cardiovascular Services; Project Management Office, Memorial Health System, Springfield, Illinois, USA ${ }^{2}$ Department of Emergency Medicine, Southern Illinois University School of Medicine, Springfield, Illinois, USA

Correspondence to

Dr Karen Baur;

Baur.Karen@mhsil.com

\section{ABSTRACT}

Acute myocardial infarction (AMI) follow-up care is a crucial part of the AMI recovery process. The American College of Cardiology's 'See You in 7 Challenge' advocates that all patients discharged with a diagnosis of AMI have a cardiac rehabilitation referral made and outpatient cardiac rehabilitation appointment scheduled to occur within 7 days of hospital discharge. A streamlined AMI cardiac rehabilitation referral and appointment scheduling process was not in place at this urban academic medical centre. To develop the streamlined processes, a Six Sigma project was initiated. Four months before the intervention, 1/38 patients with AMI (2.6\%) were scheduled to have the initial outpatient cardiac rehabilitation appointment occur within 7 days of hospital discharge, with an average 18.7 days from hospital discharge to the scheduled initial outpatient cardiac rehabilitation appointment. To reduce the time to this initial appointment, availability of outpatient cardiac rehabilitation appointments was increased, additional staff were trained in appointment scheduling and insurance verification processes and appointments were scheduled prior to hospital discharge. After intervention, the number of patients scheduled to attend an outpatient cardiac rehabilitation appointment within 7 days of hospital discharge improved to 72/79 (91.1\%) (two-proportion test, $p<0.001)$. Days from hospital discharge to first scheduled outpatient cardiac rehabilitation appointment were reduced from 18.7 days to 6.3 days (a $66.3 \%$ reduction) (Mann-Whitney U test, $\mathrm{p}<0.01$ ). Initial outpatient cardiac rehabilitation attendance within 7 days of hospital discharge increased from 1/38 (2.6\%) to 42/79 (53.2\%) (a $50.6 \%$ increase) (two-proportion test, $p<0.001$ ).

\section{INTRODUCTION}

In an urban tertiary care 500-bed hospital in Illinois, USA, with nearly 25000 discharges per year, 96 patients with acute myocardial infarction (AMI) in the residing county were discharged to home or self-care between January and April 2016. Of those 96 patients, only one $(2.6 \%)$ had an initial outpatient cardiac rehabilitation appointment scheduled to occur within 7 days of hospital discharge. In addition, our institution's risk-adjusted 30-day readmission rates for patients with AMI from January to August 2016 were $11.8 \%$, above our expected readmission rate of $9.58 \%$ and above the 2016 top quartile Centers for Medicare and Medicaid Services (CMS) peer comparison group. Further investigation revealed the root cause was lack of specific requirements to get patients into outpatient cardiac rehabilitation within a specific time frame.

The American College of Cardiology (ACC) advocates patients with AMI schedule an initial outpatient cardiac rehabilitation appointment within 7 days of hospital discharge. ${ }^{1}$ This quality initiative has been titled 'See You in 7' by the ACC's Hospital-ToHome initiative. ${ }^{2}$ The 'See You in 7 ' initiative includes tactics such as providing the patient with an appointment card and scheduling the appointment prior to discharge, all focused on promoting attendance to cardiac rehabilitation within 7 days of hospital discharge. ${ }^{23}$

Engaging patients in outpatient cardiac rehabilitation in a more timely manner promotes better patient outcomes including reduced 30-day readmission and mortality rates for the AMI patient population. ${ }^{3-6}$ According to Pack et al, providing patients with AMI with appointments within 7 days may impact patient outcomes such as readmission rates, and have an impact on the likelihood of attending the initial cardiac rehabilitation appointment. ${ }^{7}$

Evidence-based guidelines from the ACC provide a class 1 level recommendation for referral to a cardiac rehabilitation for patients with recent AMI. ${ }^{1}$ Comprehensive multidisciplinary cardiac rehabilitation programmes are a cost-effective approach to assist patients in modifying cardiac risk factors, increasing exercise capacity and improving quality of life, allowing restoration to optimal physical and psychosocial functioning. ${ }^{8-10}$ Despite the benefits of cardiac rehabilitation programmes, the services are underused with only $14 \%-35 \%$ of eligible patients with AMI participating. ${ }^{10-12}$

No specific parameters or guidelines around an appropriate time frame from AMI discharge to first scheduled outpatient cardiac rehabilitation appointment existed at our institution. Process mapping of the outpatient cardiac rehabilitation scheduling process revealed that patients were only given information about outpatient cardiac rehabilitation during their inpatient stay. 
Outpatient Cardiac Rehabilitation Process

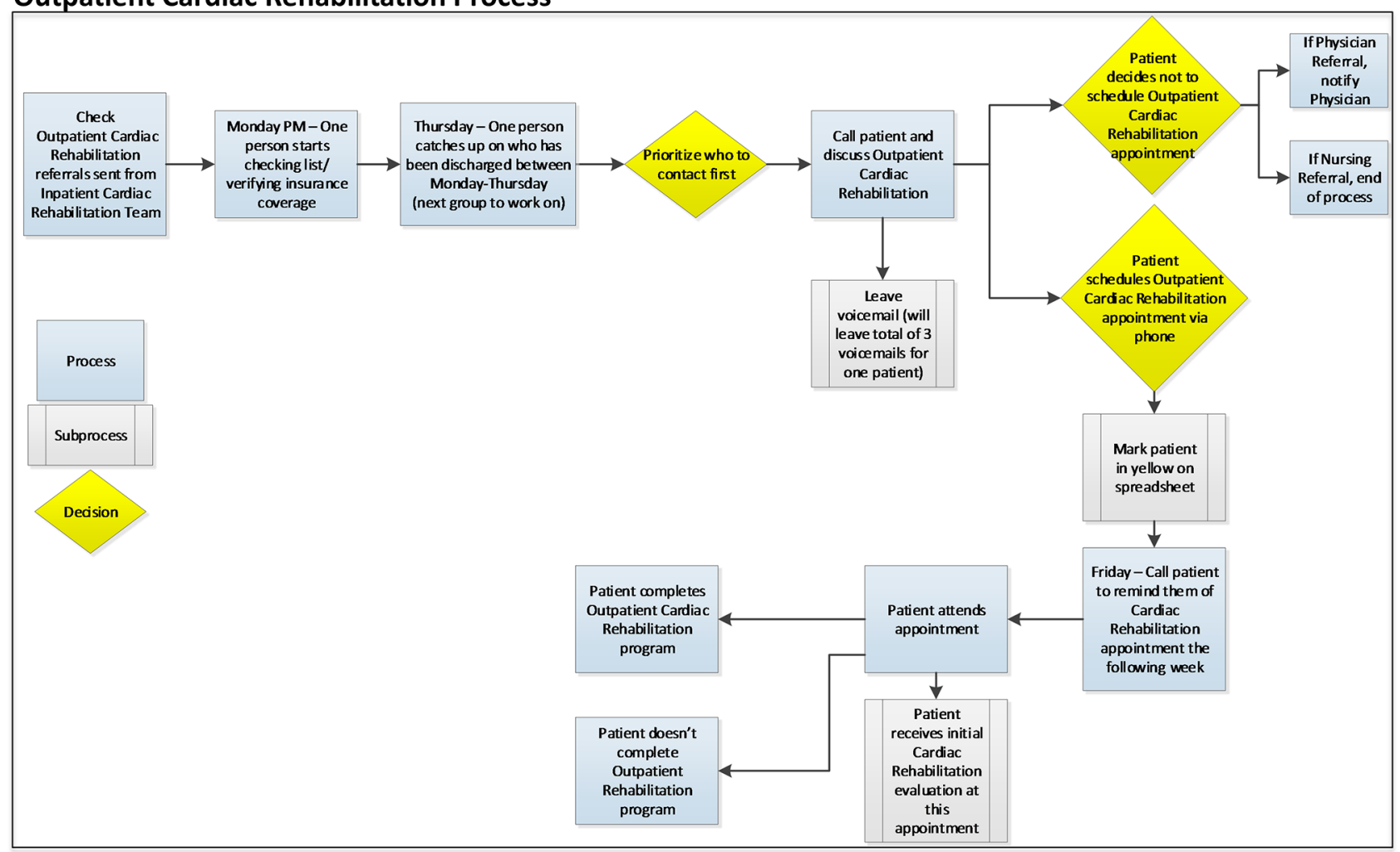

Figure 1 Before the intervention, the outpatient cardiac rehabilitation team received referrals from the inpatient cardiac rehabilitation team. One staff member verified insurance information on Monday afternoons. On Thursday, the staff member would catch up on new referrals and prioritise which patients to call and schedule an appointment. With only one staff member completing the insurance verification and appointment scheduling, a bottleneck was created and patients were not contacted to schedule their appointment until an average of 5 days after hospital discharge.

One outpatient nurse verified insurance information on Monday afternoons and on Thursday would catch up on new referrals and prioritise which patients to call and schedule appointments. Due to other duties, this staff member could only dedicate a few hours per week to complete the insurance verification and appointment scheduling, creating a bottleneck effect. On average, patients were not contacted until 5 days after hospital discharge to schedule their outpatient appointment (online supplementary figure 1) (figure 1). By the time patients were contacted to schedule their appointment, there were no available appointment slots within 7 days of their hospital discharge. When patients were asked, 'What keeps you from attending cardiac rehabilitation?' answers included not seeing the need for cardiac rehabilitation, needing to know if their insurance would cover the appointment and wanting to confirm with their physician before committing to cardiac rehabilitation.

In response to the ACC standardised best practice guidelines and 30-day AMI readmission rates, a Lean Six Sigma project was initiated. The purpose of this project was to increase the number of patients with AMI with a first outpatient cardiac rehabilitation appointment scheduled to occur within 7 days of hospital discharge. The goal was to improve this process by $40 \%$ within 3 months as measured by an appointment database. As there had been no standard in place prior to the project, the team believed a $40 \%$ improvement would be attainable. Decreasing time from discharge to first scheduled outpatient cardiac rehabilitation appointment for patients with AMI is consistent with the organisation's strategic goals to create great patient outcomes and to be a national leader for excellence in patient care.

\section{METHODS}

The study was performed at an urban tertiary care hospital with nearly 110 myocardial infarction (MI) discharges per month. On average, $80 \%$ of cases are ST-elevation MIs and $20 \%$ of cases are non-ST-elevation MIs. There are nine people on the cardiac rehabilitation team with some staff working in both inpatient and outpatient cardiac rehabilitation roles. Outpatient cardiac rehabilitation is conducted at an off-site location.

To identify process improvements to enhance quality, the Lean Six Sigma model consists of a five-step process of define, measure, analyse, improve and control. Deployment of this quality improvement methodology is designed to produce predictable and sustainable results. ${ }^{13}$ This model requires engaged stakeholders to define the core problem, dive deep into issues through data measurement and analysis, identify improvements 


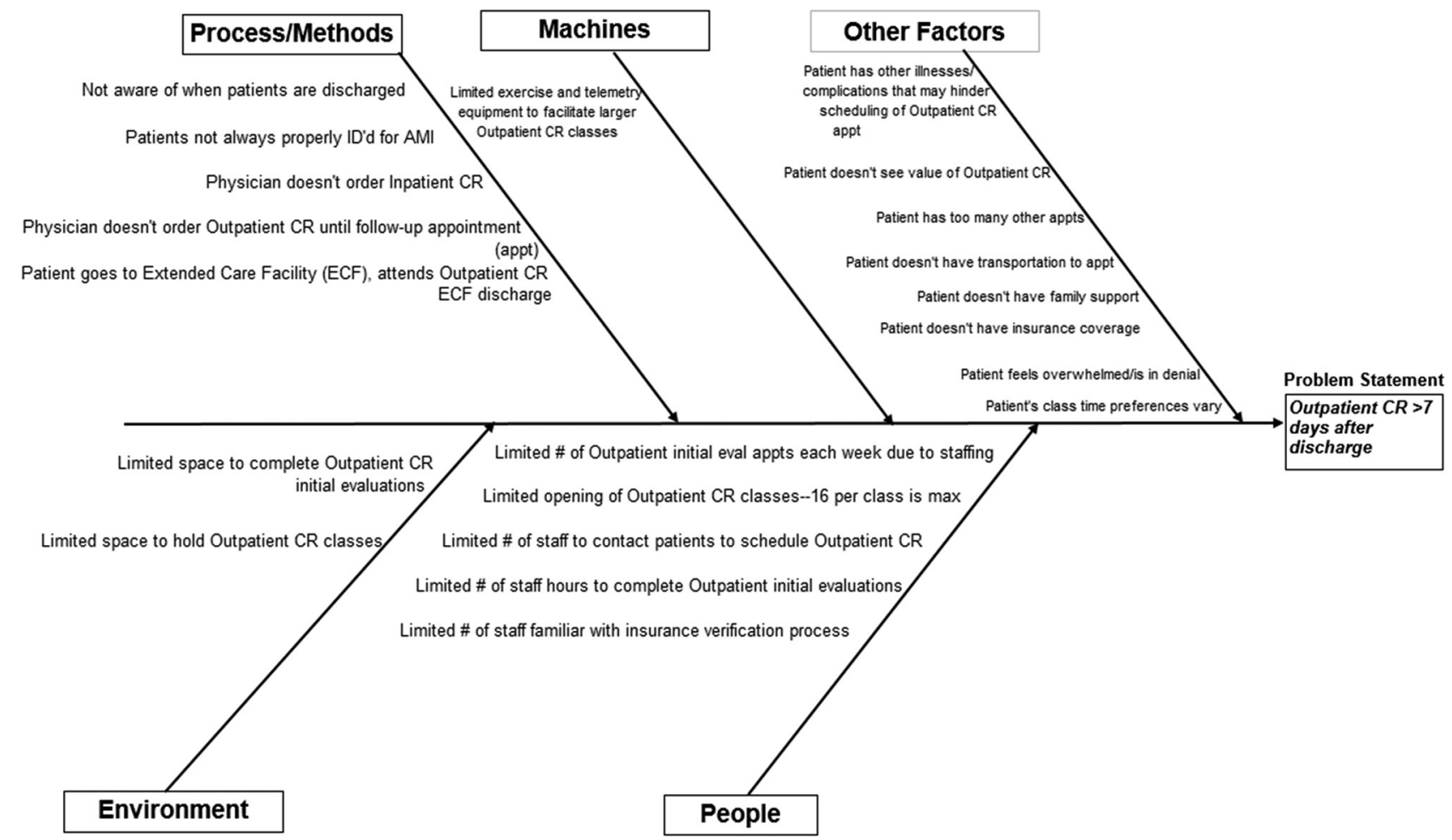

Figure 2 Fishbone diagram determined potential causes for time to initial outpatient cardiac rehabilitation (CR) appointment greater than 7 days of hospital discharge. Cause and effects were organised into categories that included environment, process, machines, people and other. AMI, acute myocardial infarction; CR, cardiac rehabilitation.

and develop control plans to ensure sustainability of the identified outcomes. The project team comprised a cardiologist, the director of cardiovascular services, the cardiopulmonary rehabilitation nurse manager, nursing staff and a patient care facilitator.

Lean Six Sigma tools used included a critical-to-quality tree and workflow process mapping (figure 1) (online supplementary figures 1 and 2). In addition, fishbone diagrams and a 5 Why's analysis revealed barriers and critical factors (X's) to scheduling the initial outpatient cardiac rehabilitation appointment to occur within 7 days of hospital discharge (figure 2). Critical X's for the project included: (1) number of available outpatient cardiac rehabilitation initial evaluation appointments within 1 week of hospital discharge; (2) timeliness of first contact to schedule initial outpatient cardiac rehabilitation appointment; and (3) number of staff able to schedule initial outpatient cardiac rehabilitation appointment and verify insurance coverage for the appointment.

Our project objective was for every patient with AMI, within inclusion criteria, to have a first outpatient cardiac rehabilitation appointment scheduled to occur within 7 days of hospital discharge. 'See You in 7' guidelines and the importance of engaging patients with AMI in outpatient cardiac rehabilitation in a more timely manner were shared with staff during team meetings and huddles. Additional outpatient cardiac rehabilitation appointment slots were opened to accommodate the increase in patients with AMI planned to attend outpatient cardiac rehabilitation within 7 days of hospital discharge. In addition, appointment slots were blocked on Thursdays to accommodate the influx of patients. Managers had to ensure adequate staffing to fill the additional appointment slots.

Staff members were cross-trained to schedule the initial outpatient cardiac rehabilitation appointments. This allowed scheduling of these appointments to occur every day of the week as opposed to the few days a week that one person previously scheduled these appointments. Colour-coded calendars that highlighted the reserved appointment slots for patients with AMI were placed in the scheduling area as visual reminders. Additionally, staff who did not work regularly were given reminders of the changes during their shifts.

Staff were cross-trained on the patient insurance verification and coverage process for outpatient cardiac rehabilitation services. A weekly rotation was assigned to staff members, which provided the opportunity for one staff member to be dedicated to this activity (in addition to other duties) each week. This allowed staff the ability to obtain the insurance verification information earlier in the process (while the patient was still an inpatient). After staff were cross-trained in scheduling and insurance verification, staff began scheduling outpatient cardiac rehabilitation appointments prior to hospital discharge. As a result, the team member completing the inpatient cardiac rehabilitation care was able to provide the insurance coverage information and answer patient questions at the time of scheduling the initial outpatient cardiac 
rehabilitation appointment. Staff members who were experienced with the insurance verification process served as resources to newly trained staff and answered any insurance verification questions. The number of staff trained to schedule and verify insurance coverage increased from one to nine team members. Process improvements were made at multiple stages of the appointment scheduling process to maintain sustainability.

The team hypothesised that changing availability of initial evaluation appointments, timeliness of initial scheduling contact and the number of staff able to make first scheduling contact and verify insurance would decrease the time from AMI patient discharge to cardiac rehabilitation appointment.

Patients aged 18 years or older with a primary or secondary diagnosis of AMI who were discharged to home or self-care and lived within the county of the hospital's outpatient cardiac rehabilitation programme were included in the project. Timeliness of initial outpatient cardiac rehabilitation appointment was measured. The operational definition stated: 'If appropriate, appointment scheduled to occur within 7 days of hospital discharge (yes/no).' A data-tracking spreadsheet was created and a control plan was put into place for longterm improvement. The control plan ensured continued monitoring and staff accountability after the project was transitioned to the cardiac rehabilitation department. The department continues to monitor the number of days from hospital discharge to first scheduled and attended outpatient cardiac rehabilitation appointments for patients with AMI. In addition, close monitoring of 30-day readmissions for this patient population continues.
Days from hospital discharge to first scheduled outpatient cardiac rehabilitation appointment were plotted using a statistical process control chart in QI Macros in Excel. Mann-Whitney U tests were used to determine differences in the number of days to first scheduled and attended appointments before and after the intervention. Two-proportion tests were used to determine the differences in the per cent of patients who declined or agreed to schedule cardiac rehabilitation, the per cent of patients with an appointment scheduled within 7 days, per cent of patients who attended their scheduled appointment and the per cent of patients who were readmitted within 30 days before and after the intervention. Data for overall 30-day readmission rates at the institution were measured from the Premier database. All statistics were performed in Minitab. A p value of $<0.05$ was considered significant.

This submission has been reviewed by the local institutional review board and was found exempt. This review board determined that this project was not research involving human subjects.

\section{RESULTS}

\section{Time to scheduled appointment}

Following the interventions, time of inpatient discharge to first scheduled outpatient cardiac rehabilitation appointment was reduced from an average of 18.7 days to 6.3 days, a $66.3 \%$ improvement $(\mathrm{p}<0.01$, Mann-Whitney $\mathrm{U}$ test) (figure 3 ). In addition, the percentage of patients who had the first outpatient cardiac rehabilitation appointment scheduled to occur within 7 days of hospital discharge increased from $1 / 38$ patients $(2.6 \%)$ to $72 / 79$

\section{Days from Hospital Discharge to First Scheduled Outpatient Cardiac Rehabilitation Appointment}

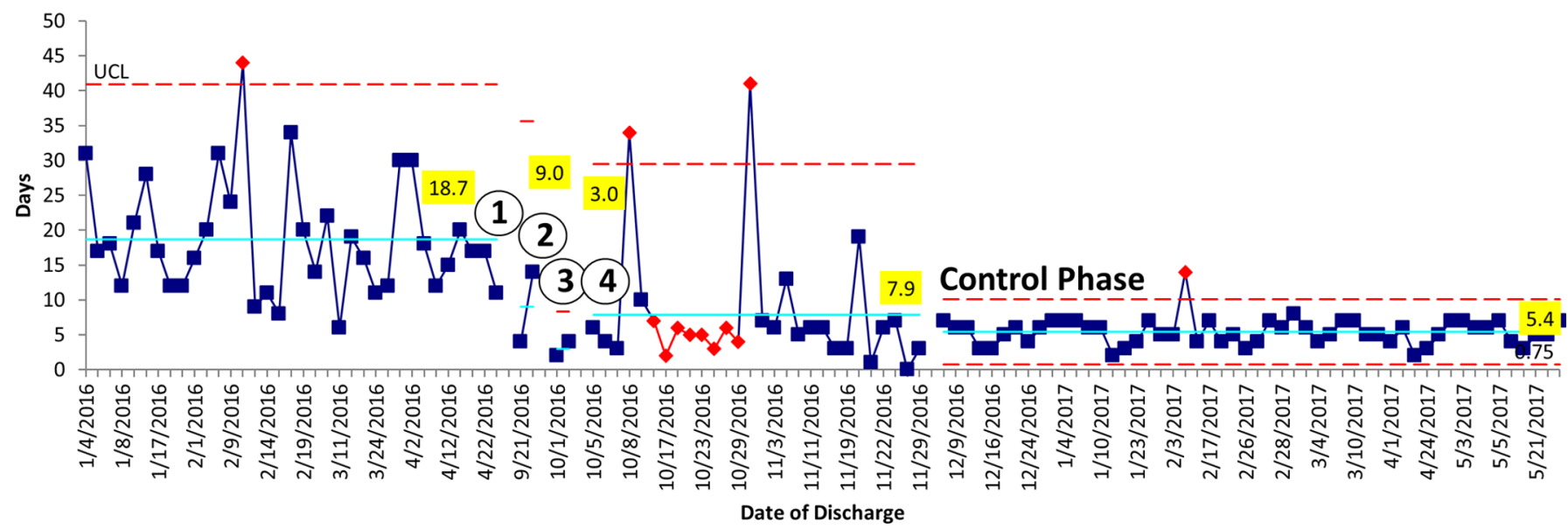

Figure 3 Time from hospital discharge to first scheduled outpatient cardiac rehabilitation appointment for patients with acute myocardial infarction (AMI) was significantly reduced from 18.7 days before intervention to 6.3 days after intervention (MannWhitney $U$ test, $p<0.01$ ). Interventions included: (1) adding additional appointment slots; (2) cross-training in scheduling; (3) cross-training in insurance verification; and (4) scheduling appointments prior to hospital discharge. Interventions 1-4 are represented by circles in the figure. The control phase began when the process was handed over to the department. The upper control limit (UCL), shown as the red dotted line, represents 3 SDs from the mean. Data points above the UCL are shown as red circles. The solid blue centreline represents the average. The string of red diamonds represents eight data points below the centreline. 
Table 1 Scheduled and attended cardiac rehabilitation appointments and 30-day readmission rates before and after intervention

\begin{tabular}{|c|c|c|c|}
\hline & $\begin{array}{l}\text { Before } \\
\text { intervention }\end{array}$ & $\begin{array}{l}\text { After } \\
\text { intervention }\end{array}$ & $P$ values \\
\hline Total AMI patient population & 96 & 190 & \\
\hline $\begin{array}{l}\text { Number of patients who declined cardiac rehabilitation/total } \\
\text { patients }\end{array}$ & $58 / 96(60.4 \%)$ & $111 / 190$ (58.4\%) & $\begin{array}{l}\text { Two-proportion test, } \\
\mathrm{p}=0.745\end{array}$ \\
\hline $\begin{array}{l}\text { Number of patients who agreed to schedule cardiac } \\
\text { rehabilitation/total patients }\end{array}$ & $38 / 96(39.6 \%)$ & 79/190 (41.6\%) & $\begin{array}{l}\text { Two-proportion test, } \\
p=0.745\end{array}$ \\
\hline $\begin{array}{l}\text { Number of patients with cardiac rehabilitation scheduled within } \\
7 \text { days/patients who agreed to schedule an appointment }\end{array}$ & $1 / 38(2.6 \%)$ & 72/79 (91.1\%) & $\begin{array}{l}\text { Two-proportion test, } \\
p<0.001\end{array}$ \\
\hline $\begin{array}{l}\text { Average days from discharge to scheduled cardiac rehabilitation } \\
\text { appointment }\end{array}$ & 18.7 days & 6.3 days & $\begin{array}{l}\text { Mann-Whitney U test, } \\
p<0.01\end{array}$ \\
\hline $\begin{array}{l}\text { Number of patients who attended cardiac rehabilitation/ } \\
\text { patients who agreed to schedule an appointment }\end{array}$ & $31 / 38(81.6 \%)$ & $58 / 79$ (73.4\%) & $\begin{array}{l}\text { Two-proportion test, } \\
\mathrm{p}=0.309\end{array}$ \\
\hline $\begin{array}{l}\text { Number of patients who attended cardiac rehabilitation within } \\
7 \text { days/patients who agreed to schedule an appointment }\end{array}$ & $1 / 38(2.6 \%)$ & $42 / 79(53.2 \%)$ & $\begin{array}{l}\text { Two-proportion test, } \\
\mathrm{p}<0.001\end{array}$ \\
\hline $\begin{array}{l}\text { Average days from discharge to attended cardiac rehabilitation } \\
\text { appointment }\end{array}$ & 21.7 days & 8.0 days & $\begin{array}{l}\text { Mann-Whitney U test, } \\
p<0.001\end{array}$ \\
\hline $\begin{array}{l}\text { Number of patients who were readmitted within } 30 \text { days/total } \\
\text { patients who attended cardiac rehabilitation within } 7 \text { days }\end{array}$ & $0 / 1(0 \%)$ & $1 / 42(2.4 \%)$ & $\begin{array}{l}\text { Two-proportion test, } \\
\mathrm{p}=0.331\end{array}$ \\
\hline $\begin{array}{l}\text { Number of patients who were readmitted within } 30 \text { days/ } \\
\text { total patients who did not attend cardiac rehabilitation within } \\
7 \text { days }\end{array}$ & 13/95 (13.7\%) & $30 / 148(20.3 \%)$ & $\begin{array}{l}\text { Two-proportion test, } \\
p=0.173\end{array}$ \\
\hline
\end{tabular}

AMI, acute myocardial infarction.

patients $(91.1 \%)$, an $88.5 \%$ improvement $(\mathrm{p}<0.01$, two-proportion test) (table 1). Improvements have been sustained for 5 months after handing the project over to the department (figure 3).

\section{Time to attended appointment}

Of the 38 patients with AMI who were scheduled to attend outpatient cardiac rehabilitation before intervention, one patient attended within 7 days of inpatient discharge $(2.6 \%)$. After intervention, 79 patients were scheduled to attend cardiac rehabilitation. Of the 79 patients, 42 attended within 7 days $(53.2 \%)$, a $50.6 \%$ improvement ( $\mathrm{p}<0.001$, two-proportion test). In addition, the time from inpatient discharge to first attended outpatient cardiac rehabilitation appointment was reduced from 21.7 days to 8.0 days after intervention, a $63.1 \%$ improvement ( $p<0.001$, Mann-Whitney U test).

\section{Thirty-day readmission rates}

In the study group, overall 30-day readmission rates were not significantly altered after intervention. However, the after intervention readmission rate for patients meeting ACC recommendations of attending cardiac rehabilitation within 7 days was $2.4 \%(1 / 42)$. Of the patients who did not attend cardiac rehabilitation within 7 days, 20.3\% $(30 / 148)$ were readmitted within 30 days of discharge. In addition, the institution's risk-adjusted 30-day readmission rates for patients with AMI from October 2016 to May 2017 were $9.03 \%$, below the expected readmission rate of
9.53\% and below the CMS top quartile peer comparison group.

Before intervention, 58/96 patients (60.4\%) failed to commit to scheduling an outpatient cardiac rehabilitation appointment. After intervention, 111/190 patients $(58.4 \%)$ declined cardiac rehabilitation. Of the 79 patients who initially agreed and were scheduled to attend cardiac rehabilitation after intervention, 21 did not attend $(26.6 \%)$. Overall after intervention, our attendance rate was $30.5 \%$ for the project's target population. Nationally, only $14 \%-35 \%$ of eligible patients with MI attend rehabilitation. ${ }^{14}$ This is another opportunity for further quality improvement interventions to improve cardiac rehabilitation attendance rates.

\section{DISCUSSION}

To reduce the time to scheduled outpatient cardiac rehabilitation appointments, availability of outpatient cardiac rehabilitation appointments was increased, staff were crosstrained to remove the 'one-person dependency' for the insurance verification and scheduling, and appointments were scheduled prior to hospital discharge. After intervention, the number of patients scheduled to attend an outpatient cardiac rehabilitation appointment within 7 days of hospital discharge improved to $72 / 79(91.1 \%)$ and days from hospital discharge to first scheduled outpatient cardiac rehabilitation appointment were reduced from 18.7 days to 6.3 days (Mann-Whitney $\mathrm{U}$ test, $\mathrm{p}<0.01$ ). 
Baker et al measured the time from hospital discharge to outpatient cardiac rehabilitation in 10 hospitals before and after they began participating in the 'See You in 7' initiative. 'See You in 7' tools used by participating hospitals included identifying patients with heart failure prior to hospital discharge, increasing the interaction between patients and outpatient providers during the inpatient stay and providing patients with documentation of the scheduled follow-up visit. In the 10 participating hospitals, the per cent of patients attending outpatient cardiac rehabilitation within 7 days of hospital discharge increased from $31.1 \%$ before intervention to $34.4 \%$ after intervention, a $3.3 \%$ improvement, compared with $2.6 \%$ of patients attending outpatient cardiac rehabilitation within 7 days before intervention and 53.2\% after intervention in our study. ${ }^{3}$ Variation in interventions implemented and individual system barriers may explain outcome differences in cardiac rehabilitation attendance within 7 days between the two studies.

A few key lessons were learnt through completion of this project. When implementing many smaller process improvements in a short time frame, allow for an adjustment period for the staff involved with the changes. This adjustment period is reflected by the variability in scheduling appointments during the first few weeks the interventions were implemented (figure 3). Other lessons learnt include the need to conduct frequent project team meetings to ensure project timelines are met and the project progresses in a timely fashion. Clearly defined measures with measurement procurement plans are crucial to accurate data collection and analysis. Finally, clear documentation of the data collection and analysis process in the baseline measurement phase facilitated data collection and analysis much easier during the process improvement phase.

Limitationsinclude ensuring stakeholders have the capacity to implement desired changes and are not constrained by resource vacancies, such as staff out on medical leave, or other barriers that may impact change implementation. Although staff were trained to schedule appointments and verify insurance, an additional limitation of the study was that knowledge of the new skill was not directly measured. An unanticipated limitation was continued patient scheduling conflicts even with the opening of additional outpatient cardiac rehabilitation appointment slots. Finally, ensuring physician stakeholder support for attendance to cardiac rehabilitation within 7 days of discharge must be obtained to cultivate patient buy-in.

The application of Six Sigma methodology resulted in sustainable change that reduced the time from hospital discharge to first scheduled and attended outpatient cardiac rehabilitation appointments for patients with AMI (figure 3) (table 1). The importance of this project should not be understated as the improvements made are consistent with best practice recommendations suggesting patients who engage in outpatient cardiac rehabilitation within 7 days of hospital discharge have better outcomes and reduced 30-day readmissions. ${ }^{46} 15$
Acknowledgements Cardiac Rehabilitation Team; Adeeb Ahmed, MD; Nathan Yeager, MBA, MOT, CLSSBB; Mitch Rogers, MBA, BSN, RN.

Contributors $A B$ contributed to study concept and design, acquisition and analysis of data, drafting of the manuscript, critical revision of the manuscript and study supervision. CJ contributed to analysis of data, drafting of the manuscript and critical review of the manuscript. DG contributed to analysis and interpretation of data and critical review of the manuscript. PH contributed to study design, acquisition of the data and critical revision of the manuscript. KB contributed to study concept and design, interpretation of data, critical revision of the manuscript and study supervision.

Funding The authors have not declared a specific grant for this research from any funding agency in the public, commercial or not-for-profit sectors.

Competing interests None declared.

Patient consent Not required.

Provenance and peer review Not commissioned; externally peer reviewed.

Open access This is an open access article distributed in accordance with the Creative Commons Attribution Non Commercial (CC BY-NC 4.0) license, which permits others to distribute, remix, adapt, build upon this work non-commercially, and license their derivative works on different terms, provided the original work is properly cited and the use is non-commercial. See: http://creativecommons.org/ licenses/by-nc/4.0/

(c) Published by the BMJ Publishing Group Limited. For permission to use (where not already granted under a licence) please go to http://www.bmj.com/company/ products-services/rights-and-licensing/

\section{REFERENCES}

1. King M. Hospital-to-Home "See You in 7" Tools Updated for Cardiac Rehab Awareness Week. American College of Cardiology. 2013 http://blog.acc.post/h2h-seeyou-in-7-tools-updated-for-cardiacrehab-awareness-week/ (accessed 3 Nov 2017).

2. See You in 7 [Internet]. American College of Cardiology: Quality Improvement For Institutions. 2013 https://cvquality.acc.org/ Initiatives/H2H/Projects/SeeYouin-7.aspx (cited 2 May 2017).

3. Baker H, Oliver-McNeil S, Deng L, et al. Regional Hospital Collaboration and Outcomes in Medicare Heart Failure Patients. JACC Heart Fail 2015;3:765-73.

4. Hernandez AF, Greiner MA, Fonarow GC, et al. Relationship between early physician follow-up and 30-day readmission among Medicare beneficiaries hospitalized for heart failure. JAMA 2010;303:1716-22.

5. Jencks SF, Williams MV, Coleman EA. Rehospitalizations among patients in the Medicare fee-for-service program. $N$ Engl $J$ Med 2009;360:1418-28.

6. Dunlay SM, Pack QR, Thomas RJ, et al. Participation in cardiac rehabilitation, readmissions, and death after acute myocardial infarction. Am J Med 2014;127:538-46.

7. Pack Q, Mansour M, Barboza J, et al. An early appointment to outpatient cardiac rehabilitation at hospital discharge improves attendance at orientation. Circulation 2013;127:349-55.

8. Arena R, Williams M, Forman DE, et al. Increasing referral and participation rates to outpatient cardiac rehabilitation: the valuable role of healthcare professionals in the inpatient and home health settings: a science advisory from the American Heart Association. Circulation 2012;125:1321-9.

9. Sanderson BK, Southard D, Oldridge N. Writing Group. AACVPR consensus statement. Outcomes evaluation in cardiac rehabilitation/ secondary prevention programs: improving patient care and program effectiveness. J Cardiopulm Rehabil 2004;24:68-79.

10. Parashar S, Spertus JA, Tang F, et al. Predictors of early and late enrollment in cardiac rehabilitation, among those referred, after acute myocardial infarction. Circulation 2012;126:1587-95.

11. Kwan G, Balady GJ. Cardiac rehabilitation 2012: advancing the field through emerging science. Circulation 2012;125:e369-73.

12. Suaya JA, Shepard DS, Normand SL, et al. Use of cardiac rehabilitation by Medicare beneficiaries after myocardial infarction or coronary bypass surgery. Circulation 2007;116:1653-62.

13. Arthur J. Lean six sigma for hospitals: Improving patient safety, patient flow and the bottom line. New York, NY: McGraw-Hill, 2016.

14. American Heart Association. Cardiac rehabilitation: putting more patients on the road to recovery. http://www.heart.org/idc/groups/ heart-public/@wcm/@adv/documents/downloadable/ucm_461340. pdf (accessed 3 Nov 2017).

15. Czarn AO, Jamrozik K, Hobbs MS, et al. Follow-up care after acute myocardial infarction. Med J Aust 1992;157:302-5. 